\title{
Rapid and Cost-effective Embryo Culture Technique for Commercial Production of Makapuno Seedlings
}

\author{
Osmundo D. Orense ${ }^{1 /}$, Erlinda P. Rillo ${ }^{2 /}$, Leo Alexie P. Imperial ${ }^{3 /}$, \\ Cristeta A. Cueto ${ }^{1}$, Angelica A. Lobos ${ }^{2} /$ and Maria Buena B. Areza ${ }^{1}$
}

\begin{abstract}
An embryo cultured Makapuno (ECM) production scheme which is simpler, faster and more low-cost than the current protocol has been developed. With improvements in the ex vitro establishment environment, the cut-off age for in vitro stage of seedlings before they can be transferred to soil has been lowered from 7 to 4 months resulting in a shorter ECM production cycle from 13 to 10 months. The improvements simplified the current ECM production technique by doing away with several complicated in vitro cultural practices and ex vitro establishment steps. Overall, the new ECM production scheme lowered the cost of production resulting in more affordable ECM seedlings for the farmers.

Financial analysis of a 10 year ECM seedling production venture projected much higher Internal Rate of Return, Benefit Cost Ratio and Net Present Value as well as shorter Payback Period with the use of the new ECM production scheme. With the new scheme, the break-even prices using marginal and full-cost operations were approximately 4 to 8 times lower than the current selling price for ECM seedlings. With these results, it is expected that more entrepreneurs will take up the technology for commercial production with a consequent massive planting of ECM and greater production of Makapuno in the country.
\end{abstract}

Keywords: Coconut, Makapuno, Embryo Culture, MYD, MAKT, IRR, NPV, BCR, Break-even Price, Payback Period

1/PCA-Albay Research Center, Banao, Guinobatan, Albay, Philippines

²/PhilHybrid Inc., Los Baños, Laguna, Philippines

3/Oileo Virgin Coconut Oil, Buraguis, Legaspi City, Philippines 


\section{Introduction}

Makapuno nut production is a lucrative business in the Philippines offering an annual income per hectare (160 palms/ha) starting from $\mathrm{PhP} 130,000$ during the initial year to $\mathrm{PhP} 350,000$ during the later years of production. This is the reason why demand for true-to-type Makapuno seedlings remains high. However, even with currently high and increasing demand for ECM seedlings, entrepreneurs seem reluctant to venture into this agribusiness undertaking due to its long payback period (PSMSI, 1999) and high production cost (Areza et al., 2003) even with the use of the current coconut embryo culture protocol which takes about 13 months to produce seedlings ready for field planting. This production cycle needs to be shortened in order to attract capitalists to venture into the embryocultured Makapuno (ECM) production business.

Moreover, many complicated cultural practices and steps involved in the current ECM production may be eliminated or simplified to reduce production costs in order to make ECM seedlings more affordable for the coconut farmers.

The lower age limit of in vitro seedlings that could undergo autotrophic growth for an earlier shift to ex vitro conditions needed to be established. Studies on photosynthetic parameters such as chloroplast ultrastructure, PEPC and RubisCO have shown that plantlets at the end of the in vitro culture process possessed several photosynthetic characteristics similar to those of acclimatized plants (Verdeil, 1996). However, these studies used completely hardened in vitro plants (ca. at least 7 month old) and did not investigate younger in vitro seedlings.

At the same time, the optimal ambient environment for ex vitro establishment of in vitro grown seedlings should also be identified before results of in vitro and ex vitro treatments on ex vitro survival can be analyzed more accurately. The soil support medium and cover to conserve the relative humidity during soil establishment also needed to be improved and biological factors such as quality of starting embryos and role of haustorium on growth of seedlings in vitro and subsequent survival ex vitro needed investigation.
Likewise, the relationship of root and leaf attributes with survival of seedlings when transferred to soil needed to be established.

This study set out to improve the current art and technique of Makapuno embryo culture. It aimed to shorten the incubation period in vitro and simplify the various steps involved in the current protocol for ECM seedling production by: (1) determining the earliest stage of in vitro seedlings that can reliably undergo photoautotrophic growth when transplanted to soil; (2) improving ambient environment for ex vitro establishment of in vitro grown seedlings; and (3) looking at relevant factors that may cause slow development of the seedlings in vitro and low survival rate ex vitro.

Finally, it is necessary to analyze the financial aspect of ECM production using the current Makapuno embryo culture protocol and the new ECM production scheme developed in this study. The resulting estimates for the Net Present Value (NPV), Benefit Cost Ratio (BCR) Internal Rate of Return (IRR), and Payback Period (PP) can then serve to stimulate entrepreneurs who may be interested in ECM production.

\section{Methodology}

Preliminary trials were conducted to identify the range of treatments to be included in the actual experiments. Actual experiments were conducted using embryos collected from nuts of Malayan Yellow Dwarf (MYD) populations and non-Makapuno nuts from previously embryo cultured Makapuno palms (MAKT) growing at PCA-Albay Research Center. Final verification experiments were conducted using Makapuno embryos. Ex vitro survival was assessed six (6) weeks after soil transplanting. Whenever appropriate, data were analysed statistically using ANOVA and DMRT, together with data from previous ECM production studies to look at trends relevant to in vitro growth and ex vitro survival of different ages of in vitro seedlings. These were used to establish the statistical significance of the results of experiments conducted in this study. 


\section{The following experiments were conducted: \\ 1). Photosynthetic capacity of different ages of in vitro seedlings}

Two (2) and three (3) month-old seedlings were cultured in Hoagland's nutrient medium for a single passage before they were transplanted to the soil support medium. Ex vitro survival of the treated seedlings were compared with the control treatment (current protocol).

Ex-vitro establishment of the treated seedlings (3 and 4 month-old) was also tried on soil-less Hoagland's medium. A pump controlled by a time switch provided a periodic flow of circulating Hoagland's nutrient solution for the plants every 15 minutes. The seedlings were kept in place in holes in Uratex ${ }^{\circledR}$ pads on an ordinary $100 \mathrm{~mm}$ diameter PVC pipe through which the Hoagland's solution flowed (Figure 1a). The whole set up was contained inside a humidity tent (Figure 1b) which was manually ventilated to prevent any high temperature build-up (i.e. more than $40^{\circ} \mathrm{C}$ ). Ex vitro survival rates of treated seedlings were compared to the control.

2). Improvement of ambient environment for ex vitro establishment of in vitro grown seedlings

A 1:1 mixture of garden soil and cocopeat was compared with the routinely used river sand as support medium in the establishment of in vitro grown seedlings. Sterilization of the soil support medium was also evaluated by comparing sterilized and non-sterilized soil support medium in terms of survival of seedlings. Sterilization of the medium was done for 30 minutes in a pressure cooker. Three (3) and four (4) month-old seedlings grown from embryos of MYD and normal nuts of MAKT were used in the experiments. Ordinary clear plastic bags were used as cover to maintain high relative humidity for the transplanted seedlings.

In a separate experiment, utilization of a communal humidity tent (Figure $1 \mathrm{~b}$ ) to preserve high relative humidity during the initial phase of ex vitro establishment of seedlings was compared with the use of individual ordinary clear plastic bag covers (Figure 2) as used in the ex vitro
Figure 1. a) Ex vitro establishment set-up using circulating Hoagland's solution. b) Humidity tent covering the whole set-up

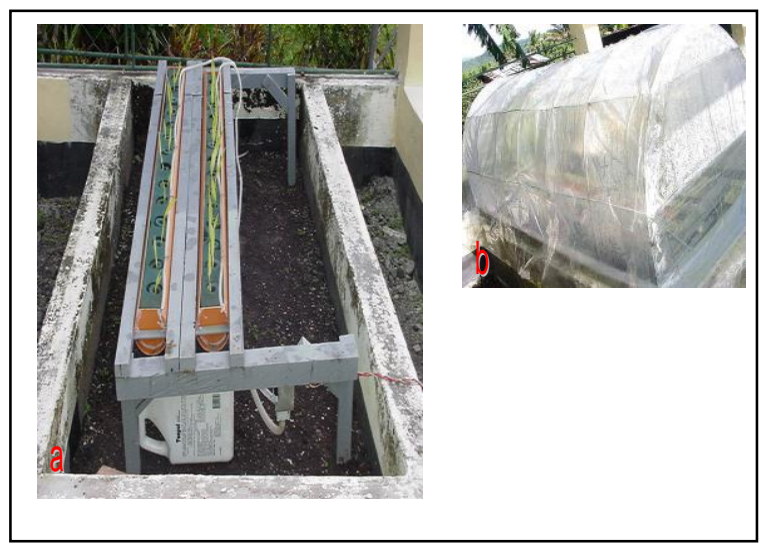

Figure 2. Clear plastic bag covers used to maintain high relative humidity during ex vitro establishment of in vitro coconut plants as recommended in the current protocol

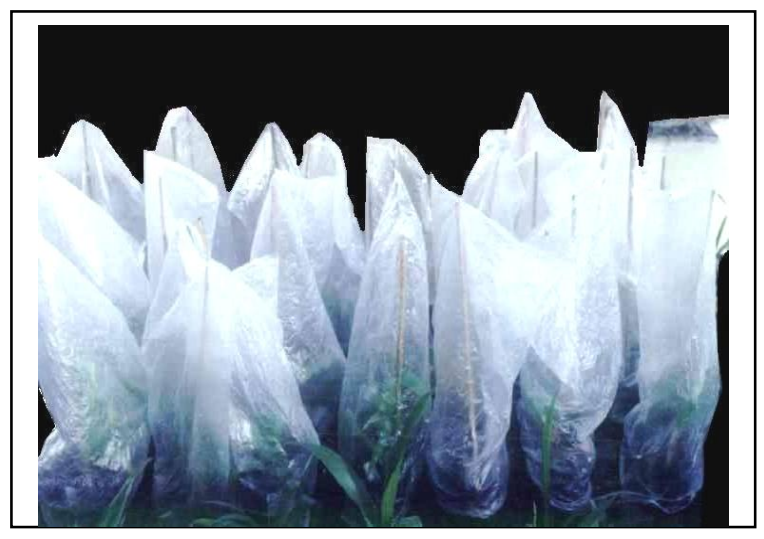

establishment procedure of the current protocol. Three (3) month-old in vitro grown MYD seedlings were used in the experiment.

\section{3). Internal factors that may influence development of seedlings in vitro and survival ex vitro}

3a). Partial removal of haustorium

During in vitro stage of the culture, the treatments were applied to germinated embryos as follows: 
T1 Haustorium partially removed after germination

T2 Haustorium partially removed 4 weeks after germination

T3 Haustorium intact (control)

Only embryos that germinated after 4 weeks were used in the experiment. Shoot length and fresh weight of cultures just before they were established ex vitro were compared among the three (3) treatments used. The cultures were transplanted after 5 months in vitro following the current ex vitro establishment procedure with modifications according to the results of Experiment 2.

3b). Density of embryo

Coconut embryos either float or submerge when they are placed into liquid nutrient medium. Germination and further development as well as survival during ex vitro establishment of initially floated and submerged embryos were compared.

\section{4). In vitro hardening by proper positioning of seedlings in vitro}

Two (2) month-old rooted seedlings were planted in such a way that only the roots and tips of the haustoria were in contact with the liquid medium. The plants were fixed at this position inside the test tube using sterilized pieces of polyurethane foam. The usual planting procedure wherein the plants were planted with parts of the stem submerged in the medium served as control.

Initial and final fresh weights of the plants were recorded in order to determine the weight gained for each treatment. The final weights were recorded two (2) months after treatment. Ex vitro survival rates for the two (2) treatments were compared.

\section{5). Analysis of data from previous ECM production studies}

Relevant raw data gathered from previously conducted research were reconsolidated and analyzed. Analysis was focused on possible in vitro growth and ex vitro survival trends that may relate to the results of the experiments

\section{6). Integration of results to the Makapuno embryo culture protocol: verification and economic analysis of the modified protocol}

Experiments using Makapuno embryos were conducted to confirm results of the experiments that were conducted using embryos from normal nuts. Based on results of the confirmatory experiments, necessary adjustments were made on the current embryo culture protocol to come up with a new scheme for ECM production.

An economic analysis of a 10-year ECM production project involved the use of the current and the new protocols. Annual cash flows were estimated based on 2006 prices. NPV, BCR, IRR and PP were computed and compared between the two protocols. Factors of 7, 10 and $15 \%$ were considered in the discounted analysis. Break-even analyses for 410 month incubation periods in vitro were also made using marginal costing (i.e., only variable costs were involved) and full costing (i.e., fixed and variable costs were involved).

\section{Results and Discussion}

\section{1). Photosynthetic capacity of different ages of in vitro seedlings}

The intervening one (1) month passage in Hoagland's medium prior to ex vitro establishment did not affect ex vitro survival of MAKT seedlings. On the other hand, the same treatment resulted in significantly lower percentage of ex vitro survival for MYD seedlings (Table 1). The apparent sensitivity of MYD seedlings to the quality of nutrient medium in vitro may be attributable to the higher metabolic rate of MYD, which are earlier maturing than MAKT.

Nevertheless, the observed ability of both cultivars to survive during the 1 month in vitro incubation in Hoagland's medium suggested that in vitro seedlings are capable of autotrophic growth even at an early age of two (2) months. The plants relied on $\mathrm{CO}_{2}$ from the air as source of carbon for autotrophic growth because Hoagland's solution lacks sugar. The observed 
photosynthetic readiness of 2 month-old in vitro seedlings suggests that they maybe already fit for ex vitro establishment.

Ex vitro survival of three (3) month-old seedlings was generally comparable with 4 month-old seedlings. This result indicated that under PCA-ARC laboratory condition, 3 monthold coconut embryo cultured seedlings were ready for soil establishment. However, in vitro growth of seedlings in Hoagland's was obviously slower than in Y3 medium. Likewise, secondary roots did not develop or were poorly developed in Hoagland's nutrient medium (Figure 3). Nevertheless, the hardiness of the 3 month-old seedlings was comparable to well-rooted 4 month-old seedlings grown in Y3 medium as indicated by their survival during ex vitro establishment.

Results of another experiment showed that survival rates of three (3) and four (4) month-old normal MAKT and MYD seedlings grown in vitro were not significantly different with respect to the two (2) ex vitro establishment methods tried (Table 2). The result indicated that in vitro seedlings can also be established ex vitro in soilless medium. Established seedlings continued to grow when transplanted to soil inside the screenhouse or nursery. This ex vitro establishment method has great potential for large scale commercial production of elite coconuts, such as Makapuno, using embryo culture techniques. Since the nutrient composition of Hoagland's solution is more exactly defined than the soil-cocopeat mixture, which varies unpredictably from one batch of mixture to another, using this solution will make a consistent ex vitro establishment medium. Furthermore, this will pave the way for a mechanized ex vitro establishment procedure for in vitro grown coconut or other crops whenever applicable.

\section{2). Improvement of ambient environment for ex vitro establishment of in vitro grown seedlings}

Ex vitro survival of three (3) month-old MYD in the routinely used sterilized pure sand medium was significantly higher when a communal humidity tent was used (Table 3 ). The higher survival of seedlings inside the humidity tent could be due to the good headspace provided for the seedlings. Due to the limited size of the clear plastic bag covers, build up of high temperature within the head space of the seedling may occur and may adversely affect the survival of seedlings.

Illuminance inside the humidity tent was around 45,000 Lux at noon on a partly cloudy day when illuminance outside was around 75,000 Lux. With a clear sky, when illuminance outside reached 130,000 Lux it was 72,000 Lux inside the humidity tent. The highest temperature recorded inside the humidity tent was $38^{\circ} \mathrm{C}$. Temperature inside the plastic bag cover reached as high as $49^{\circ} \mathrm{C}$.

In a separate experiment, survival of 3 month-old seedlings, noted 6 weeks after soil planting, was significantly higher in soilcocopeat mixture than in pure sand. For four (4) month-old seedlings, the two (2) soil support media were not significantly different in terms of ex vitro survival of four (4) month-old seedlings. Soil-cocopeat mixture provides better aeration and has higher water holding capacity than pure sand. These facts could well explain the higher survival of three (3) month-old seedlings in the soil-cocopeat medium. The beneficial effect of this soil support medium was probably insignificant for older or more hardened four (4) month-old seedlings hence, their survival rates in the two soil support medium were comparable.

Sterilization of the oil support medium had no significant effect on ex vitro survival of either three (3) or four (4) month-old seedlings (Table 4). Sterilized and non-sterilized soil support media did not differ significantly in terms of survival of seedlings during ex vitro establishment. This suggests that in vitro seedlings as young as three (3) month in vitro can tolerate any harmful effects of microorganisms that may be present in nonsterilized soil medium. It may also be inferred that the fungicide solution used to dip the seedlings prior to soil planting is enough to avoid fungal infection during soil establishment of the seedlings. 
Table 1. Percentage ex vitro survival of 3 and 4 month-old MAKT and MYD seedlings as affected by intervening 1 month passage in Hoagland's medium prior to ex vitro establishment

\begin{tabular}{|c|c|c|c|c|}
\hline \multirow{2}{*}{$\begin{array}{c}\text { Treatment } \\
\text { (Final } \begin{array}{c}\text { Subculture medium in } \\
\text { vitro) }\end{array}\end{array}$} & \multicolumn{3}{|c|}{ Survival of Seedlings (\%) } \\
\cline { 2 - 5 } & MAKT & \multicolumn{2}{c|}{ MYD * } \\
\cline { 2 - 5 } & 3 month-old & 4 month-old & 3 month-old & 4 month-old \\
\hline Hoagland's & 98.22 & 97.32 & $96.43 \mathrm{~b}$ & $93.75 \mathrm{c}$ \\
\hline Y3 (control) & 98.22 & 98.22 & $99.11 \mathrm{a}$ & $97.32 \mathrm{~b}$ \\
\hline
\end{tabular}

${ }^{\mathrm{ns}}=$ Not significantly different at $5 \%$ level

* = Significantly different at 5\% level; values followed by the same letter in the same block (cultivar) are not significantly different.

Table 2. Percentage ex vitro survival of 3 and 4 month-old MAKT and MYD seedlings in two (2) support medium for $e x$ vitro establishment

\begin{tabular}{|l|l|l|l|c|}
\hline \multirow{2}{*}{$\begin{array}{c}\text { Treatment } \\
\text { Support medium for ex vitro } \\
\text { establishment) }\end{array}$} & \multicolumn{4}{|c|}{ Survival of Seedlings (\%) ${ }^{\mathrm{ns}}$} \\
\cline { 2 - 5 } & \multicolumn{3}{|c|}{ MAKT } & \multicolumn{2}{c|}{ MYD } \\
\cline { 2 - 5 } & $\mathbf{3}$ month-old & 4 month-old & 3 month-old & 4 month-old \\
\hline Circulating Hoagland's solution & 99.11 & 99.11 & 96.43 & 93.75 \\
\hline 1:1 soil-cocopeat mixture & 97.32 & 98.22 & 99.11 & 97.32 \\
\hline
\end{tabular}

${ }^{\mathrm{ns}}=$ Not significantly different at $5 \%$ level

Table 3. Ex vitro survival of 3 month-old MYD seedlings in communal humidity tent and ordinary clear plastic bag covers

\begin{tabular}{|ll|c|}
\hline \multicolumn{1}{|c|}{ Treatment } & Ex vitro Survival of Seedlings (\%) \\
\hline T1 & Humidity tent (communal) & $100 a$ \\
\hline T2 & Clear plastic bag (individual) & $96 \mathrm{~b}$ \\
\hline \hline
\end{tabular}

Table 4. Ex vitro survival of 3 and 4 month-old MAKT and MYD seedlings as affected by types and sterilization of soil support medium

\begin{tabular}{|c|c|c|c|c|}
\hline \multirow{2}{*}{ Treatment } & \multicolumn{4}{|c|}{ Ex vitro Survival of Seedlings (\%) } \\
\cline { 2 - 5 } & \multicolumn{3}{|c|}{ 3 month-old } & \multicolumn{2}{c|}{ 4 month-old } \\
\cline { 2 - 4 } & MAKT & MYD & MAKT & MYD \\
\hline Soil support & $*$ & $*$ & $n s$ & $n s$ \\
\hline Soil - cocopeat mixture & $99.11 \mathrm{a}$ & $98.22 \mathrm{a}$ & 99.11 & 97.32 \\
\hline Pure sand & $97.32 \mathrm{~b}$ & $96.43 \mathrm{~b}$ & 98.22 & 98.22 \\
\hline Sterilization & $n s$ & $n s$ & $n s$ & $n s$ \\
\hline Sterilized & 98.22 & 99.11 & 98.22 & 95.54 \\
\hline Non-sterilized & 98.22 & 96.43 & 97.32 & 95.54 \\
\hline
\end{tabular}

*Significantly different at $5 \%$ level. Means followed by the same letter in the same block are not significantly different at 5\% level of DMRT

Ns Not significantly different at $5 \%$ level 
The experiment clearly pointed out the beneficial effect of using soil-cocopeat mix over pure sand. Elimination of sterilization procedure for the soil support medium saved time, effort and logistics during soil establishment of in vitro grown coconut seedlings. This will contribute to lowering the cost of producing true-to-type Makapuno seedlings using embryo culture technique.

\section{3). Internal factors that may influence development of seedlings in vitro and survival ex vitro}

\section{3a). Partial removal of haustorium}

Partial removal of the haustoria immediately after or 1 month after germination of embryos had no significant effect on in vitro growth performance of seedlings in terms of shoot length, fresh weight and ex vitro survival of MYD seedlings (Table 5). While the haustorium plays a significant role in endosperm hydrolysis and mobilization of nutrients during germination and initial shoot growth in vivo, this may not be true for in vitro condition considering the insignificant effect of partial removal of the haustorium in terms of growth of seedlings. The possibility that it can store nutrients that can be consumed by the seedlings during ex vitro establishment is unlikely since survival rates of seedlings with intact and partially removed haustoria were not significantly different. It was also observed that the haustoria of developing seedlings were often under-developed and sometimes inconspicuous in vitro. In contrast, when growth of the haustoria sometimes filled the circumference of the test-tubes it was difficult to take out the seedlings during transferring. Based on these findings, haustoria may be partially removed after germination in order to avoid this identified difficulty during subculturing. This will contribute to higher efficiency especially when commercial application of the embryo culture technique is involved.

\section{3b). Density of embryo}

Of all the embryos planted, $96 \%$ floated on the medium while only $4 \%$ submerged (Table 6 ). Except when contaminated, submerged embryos floated after 3 - 7 days in culture. The germination rates were comparable between embryos that initially floated and those that submerged upon planting. With respect to growth of seedlings, embryos that floated at planting displayed significantly lower frequency of stunting. Subsequently, significantly higher survival rate during ex vitro establishment was exhibited by seedlings which developed from embryos that initially floated during planting. With this result, efficiency of the coconut embryo culture technique may be improved by initially culling the submerged embryos. Although submerged embryos may be discarded when the number of embryos is not limiting, this may not be wise for Makapuno embryos due to the rarity of this type of coconut.

\section{4). In vitro hardening by proper positioning of seedlings in vitro}

In vitro growth of MYD seedlings in terms of shoot length and fresh weight was generally slower when seedlings were planted in such a way that only the roots and tip of the haustorium were in contact with the nutrient medium (T1) compared when the roots, haustorium and part of the stem were submerged in the medium (T2) (Figure 4, Table 7) showing that absorption of nutrient by the growing seedlings was greatly reduced when only the roots and tip of the haustorium were in contact with the nutrient medium. Hence, growth of the seedlings relied greatly on nutrient absorption through the stem and petioles. However, survival of seedlings during ex-vitro establishment was not significantly different between the two treatments. This indicated that orienting the seedlings in vitro in such a way that the only the roots and tip of the haustorium are submerged in the nutrient medium is not necessary to increase the ex vitro survival of seedlings. Furthermore, readiness of the seedlings for ex vitro establishment should not be measured by the size or weight of the seedlings. For better growth in vitro, it is suggested that the basal part of the stem and petioles be kept in contact with the nutrient medium. Trimming of the roots may be necessary to keep the seedlings in proper contact with the medium. 
Figure 3. Three (3) month-old seedlings from Malayan Yellow Dwarf embryos that have been planted in Hoagland's (seedlings 1 \& 2) for 1 month and Y3 medium (seedlings $3 \& 4$ ) continuously

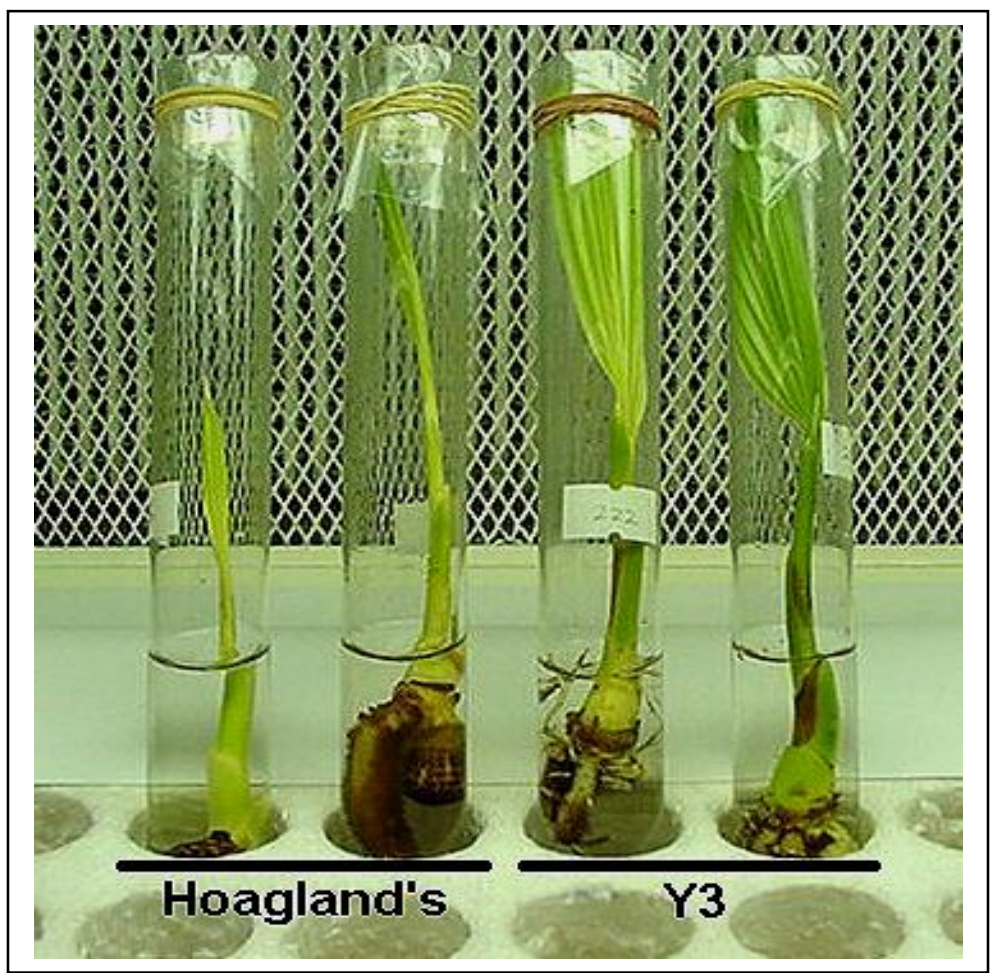

Figure 4. Four (4) month-old MYD seedlings planted normally (T2) and oriented in such a way that only the roots and tips of haustoria are in contact with the liquid medium (T1)

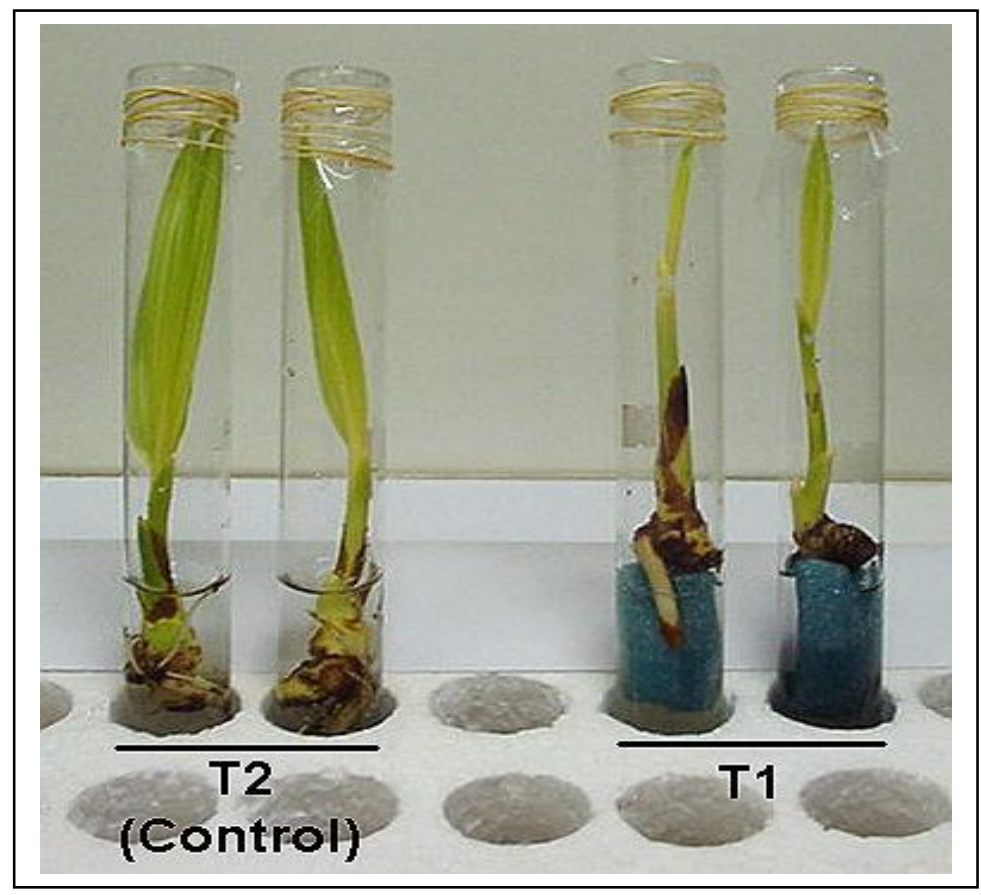


Table 5. Effect of removing the haustorium on in vitro growth performance of embryos from open pollinated MYD and survival of seedlings during $e x$ vitro establishment

\begin{tabular}{|c|c|c|c|c|}
\hline \multirow{2}{*}{\multicolumn{2}{|c|}{ Treatment }} & \multicolumn{2}{|c|}{ Growth Parameter } & \multirow{2}{*}{$\begin{array}{c}\text { Ex vitro } \\
\text { Survival } \\
(\%) \\
(\%)\end{array}$} \\
\hline & & $\begin{array}{l}\text { Mean Shoot } \\
\text { Length ns }(\mathrm{cm})\end{array}$ & $\begin{array}{l}\text { Mean Fresh } \\
\text { Weight }{ }^{\text {ns }}(g)\end{array}$ & \\
\hline & $\begin{array}{l}\text { Haustorium partially removed after } \\
\text { germination }\end{array}$ & 12.23 & 5.86 & 100 \\
\hline & $\begin{array}{l}\text { Haustorium partially removed } 1 \text { month after } \\
\text { germination }\end{array}$ & 12.54 & 6.20 & 100 \\
\hline T3 & Haustorium Intact & 12.14 & 5.88 & 100 \\
\hline
\end{tabular}

Table 6. Frequency of occurrence and germination rate of floating and sinking MYD embryos and subsequent growth of seedlings

\begin{tabular}{|l|c|c|c|c|}
\hline \multirow{2}{*}{ Parameter } & \multirow{2}{*}{$\begin{array}{c}\text { Proportion } \\
(\%)\end{array}$} & \multicolumn{2}{|c|}{ Growth performance } & \multirow{2}{*}{$\begin{array}{c}\text { Ex vitro survival } \\
(\%)\end{array}$} \\
\cline { 3 - 4 } & $96 a$ & 73.18 & $11.54 \mathrm{bs}$ & $82.28 \mathrm{a}$ \\
\hline Floating & $4 b$ & 72.73 & $18.18 \mathrm{a}$ & $63.64 \mathrm{~b}$ \\
\hline Submerged & & $\begin{array}{c}\text { Germination } \\
(\%)\end{array}$ & \\
\hline
\end{tabular}

Table 7. In vitro growth performance (Data gathered after 5 month in vitro) and ex-vitro survival of seedlings grown from embryos of MYD as affected by two planting orientations

\begin{tabular}{|c|c|c|c|}
\hline \multirow[b]{2}{*}{$\begin{array}{l}\text { Treatment (Part of the seedlings } \\
\text { submerged in the nutrient medium) }\end{array}$} & \multicolumn{2}{|c|}{ Growth Parameter } & \multirow[b]{2}{*}{ Ex vitro Survival ${ }^{\mathrm{ns}}(\%)$} \\
\hline & $\begin{array}{l}\text { Mean Shoot } \\
\text { Length }(\mathrm{cm})\end{array}$ & $\begin{array}{c}\text { Mean Fresh } \\
\text { Weight }(g)\end{array}$ & \\
\hline $\begin{array}{l}\text { T1 Only the roots and tip of the } \\
\text { haustorium }\end{array}$ & $7.68 b$ & $4.83 b$ & 80.12 \\
\hline $\begin{array}{ll}\text { T2 } & \text { Roots, haustorium and base of } \\
& \text { stem (Control) }\end{array}$ & $10.14 a$ & $6.23 a$ & 78.03 \\
\hline
\end{tabular}




\section{5). Analysis of data from previous ECM production studies}

Analysis of ECM production data from embryos initiated from January to May 2005 revealed that the ages of ECM taken out of the laboratory for soil establishment ranged from 3 11 months (Figure 5). Most of the seedlings transplanted to the soil were 4-8 months old. A decreasing trend for survival was seen as the seedlings aged in vitro. This finding suggests that younger in vitro seedlings have a better chance of survival during soil establishment than older seedlings. It was obvious that most of the seedlings were established in the soil too late because of the requirement for profuse root as recommended in the current protocol.

Moreover, analysis of other data revealed that the periodic increment in shoot or leaf length noted from the second to the fifth passage periods had a declining trend curve indicating a declining periodic growth rate as the seedlings aged in vitro (Figure 6). The higher growth rate of younger seedlings in vitro may be attributable to higher adaptability of 3 month-old seedlings to ex vitro conditions. On the other hand, the lower percentage of survival of older seedlings may be due to culture shock. The long incubation in vitro could have caused excessive dependency of older seedlings to in vitro conditions, negatively affecting their adaptability when transferred to the ex vitro environment.

Further analysis of the production data put values to some important points of concern in the production of Makapuno using embryo culture technique (Table 8). Germination of Makapuno embryos was realized on $72 \%$ of all embryos planted. Discarded cultures due to contamination reached $4 \%$ contributing to the total loss in vitro of about $30 \%$. With soil establishment survival of about $97 \%$, the overall percentage recovery from initial embryos to nursery hardened seedlings was estimated to be about $68 \%$.

6). Integration of results to the Makapuno embryo culture protocol: verification of the modified protocol and comparative economic analysis
Experiments using Makapuno embryos were carried out based on analyses of results of previous experiments.

The efficiency of a communal humidity tent over plastic bag covers, in conserving relative humidity during ex vitro establishment of MYD and normal MAKT seedlings, was verified using ECM seedlings. Survival of selected three (3) month-old rooted Makapuno seedlings which possessed at least one true leaf was significantly higher when communal humidity tent was used than when individual clear plastic bag cover was utilized during ex vitro establishment (Table 9). The use of communal humidity tent proved more efficient in ensuring higher ex vitro survival of in vitro grown Makapuno seedlings.

Culture of Makapuno embryos revealed that at three (3) months in vitro, ECM seedlings had varying extent of root and leaf development. During soil establishment, survival of seedlings with at least one (1) true leaf differed according to the extent of root development (Table 10). Surprisingly, three (3) month-old seedlings with only primary root(s) exhibited a higher percentage survival during soil establishment than seedlings possessing both primary and secondary roots. This indicated that secondary roots of three (3) month-old seedlings are better initiated ex vitro. The presence of more secondary roots during soil establishment may not be advantageous. The tender secondary roots are subject to breakage or injury during soil transplanting and may cause death of some seedlings.

According to the current Makapuno embryo culture protocol, seedlings should be ready for soil establishment when profuse secondary and tertiary roots have developed. Due to variation in their development in vitro, seedlings were taken out of the culture vessels for soil establishment at different times as they become ready (i.e., the seedlings that have developed profuse secondary and tertiary roots)

The findings that younger seedlings had a higher survival rate than older seedlings will revolutionize the Makapuno embryo culture technique. This will clearly shorten the in vitro 
Figure 5. Proportion of different ages of Makapuno seedlings (\%) taken out of the culture vessel for ex vitro establishment and their corresponding percentage survival ex vitro. (From January-May 2005 ECM Production Data, PCA-Albay Research Center)

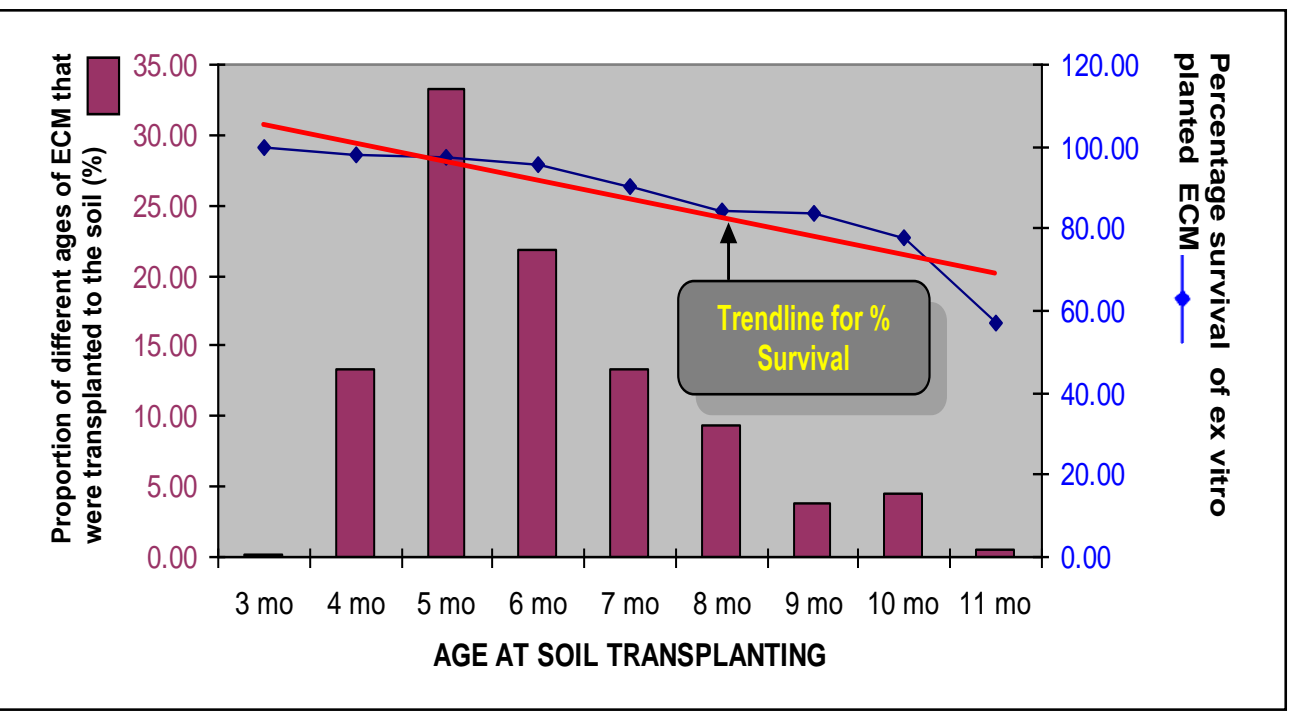

Figure 6. In vitro growth pattern of Makapuno seedlings in terms of periodic (monthly) increment in shoot/leaf length after embryo germination until the $5^{\text {th }}$ passage period

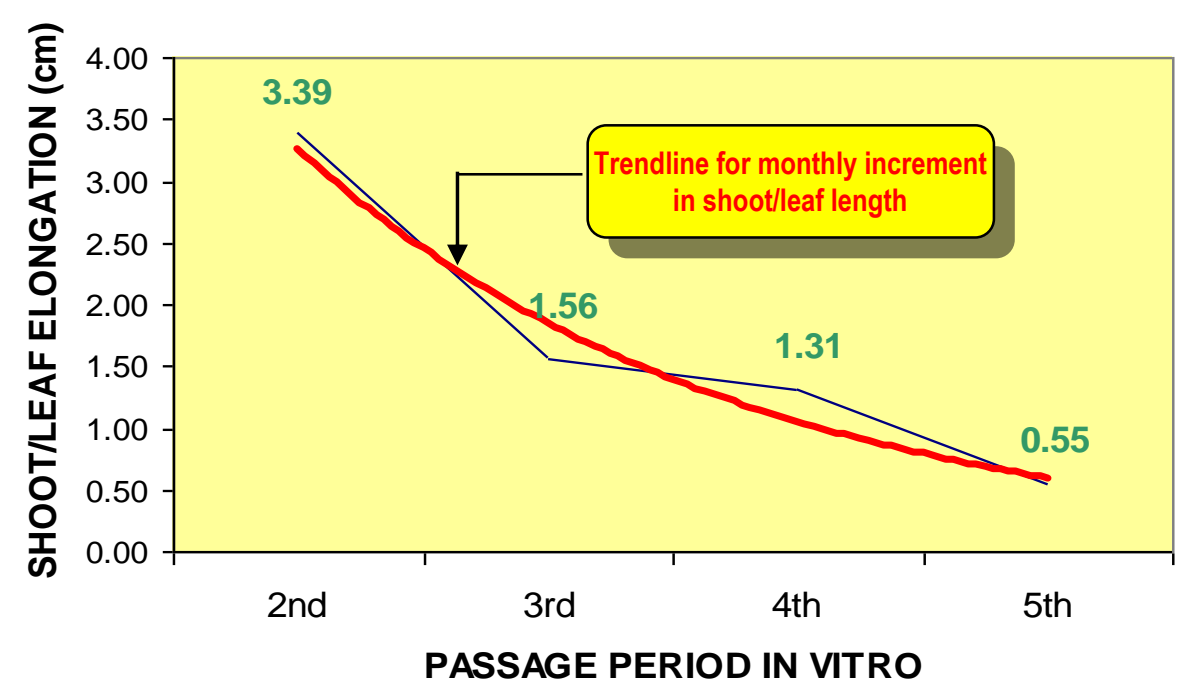


Table 8. Assessment of important points of concern in the production of Makapuno seedlings using the current Embryo Culture Technique. (Data from Jan-May 2005 ECM Production Data, PCA-Albay Research Center)

\begin{tabular}{|l|c|}
\hline \multicolumn{1}{|c|}{ Factor / Concern } & Value (\%) \\
\hline A. Germination & 72.57 \\
\hline B. Contamination in vitro & 3.53 \\
\hline C. Survival in vitro $[\mathrm{C}=\mathrm{A} \times[(100-\mathrm{B}) / 100]$ & 70.00 \\
\hline D. Survival ex vitro & 97.00 \\
\hline E. Recovery from embryo to hardened seedlings $(\mathrm{E}=\mathrm{C} \times \mathrm{D})$ & 67.90 \\
\hline
\end{tabular}

Table 9. Ex vitro survival of three (3) month-old Makapuno seedlings (with at least 1 expanded leaf and 1 primary root) in communal humidity tent and ordinary clear plastic bag cover

\begin{tabular}{|c|c|}
\hline Treatment & Ex vitro Survival $(\%)^{*}$ \\
\hline T1 Humidity tent (communal) & $100 a$ \\
\hline T2 Clear plastic bag (individual) & $92 b$ \\
\hline
\end{tabular}

* Assessed 6 wk after soil planting

Table 10. Percentage survival of 3 month old Makapuno seedlings with different stages of root development regardless of leaf development

\begin{tabular}{|l|c|}
\hline \multicolumn{1}{|c|}{ Type of Root Present } & Ex vitro Survival (\%) \\
\hline Primary Roots Only & 100.00 \\
\hline Primary + Secondary Roots & 85.00 \\
\hline
\end{tabular}

Table 11. Frequencies of selected leaf and root attributes of 3 and 4 month-old in vitro Makapuno seedlings

\begin{tabular}{|l|c|c|}
\hline \multicolumn{1}{|c|}{ Attribute } & $\begin{array}{c}\text { 3 month-old } \\
(\%)\end{array}$ & $\begin{array}{c}\text { 4 month-old } \\
(\%)\end{array}$ \\
\hline With at least 1 true leaf (partially or fully expanded) & 78.38 & 99.07 \\
\hline With at least 1 primary root & 100 & 100 \\
\hline
\end{tabular}


incubation of the seedlings leading to a shorter production cycle. Although 3 month-old seedlings could be taken out of the culture vessels for soil establishment, it was observed that significant numbers had under-developed shoots (Figure 7a). Comparing the leaf and root attributes between 3 and 4 month-old in vitro Makapuno seedlings, all have developed at least one (1) primary root. Only about $78 \%$ of 3 month-old seedlings have a partially or fully expanded leaf (Table 11). Almost $100 \%$ of 4 month-old in vitro seedlings have this leaf attribute (Figure $7 b$ ) which is required in order to qualify the seedlings for soil establishment.

With all these findings, it was recommended for commercial production of Makapuno using embryo culture technique, that four (4) in vitro months be set as the cut-off age prior to ex vitro establishment of seedlings. Moreover, as the seedlings are incubated in long test tubes $(25 \times 200 \mathrm{~mm})$ during this stage of development they are still easy to handle (Figure 7c) With the current protocol, the seedlings have to be transferred to bigger bottles with clear plastic bag extension after this stage to accommodate the growing seedlings (Figure 7d). Bigger bottles occupy larger space inside the autoclaves during sterilization; hence, less bottles are autoclaved at one time. Besides, fixing the plastic bag extension is laborious and requires care and skill to avoid contamination of the cultures. Based on these considerations, the current Makapuno embryo culture protocol was revised. The in vitro stage was shortened by 3 months (i.e., from 7 to 4 months). With a period of six (6) months for ex vitro establishment and hardening of ECM seedlings in the screenhouse and nursery before they can be sold and planted out, the whole cycle from embryo to nurseryhardened seedling was reduced from 13 to 10 months (Table 12).

Due to the shorter duration of incubation in vitro, ECM seedlings that were produced using the new scheme were smaller than when they were produced using the current protocol (Figure 8). Nevertheless, seedling size was not expected to affect their survival in the field. The smaller size, though, may initially affect the trading of the produced ECM due to the acknowledged (but unfounded) preference of farmers for bigger seedlings. On-farm trials and roadside demonstration plots will solve this problem. On the other hand, experiments related to nutritional requirement for optimal growth of ECM seedlings in the nursery is on-going at the PCA-Albay Research Center. Faster growth of ECM in the nursery will improve turn-over and satisfy the preference of farmers for bigger plants.

With a grant from DOST-PCARRD, the results prompted the construction of a strong and large capacity humidity chamber (Figure 9) for full adoption of the new ECM production scheme.

The profitability of a 10-year Makapuno seedling production project using the shortened protocol which is being proposed in this paper was compared with that using the current protocol. Both projects involved the construction of a laboratory building screenhouse and nursery in a leased $500 \mathrm{sqm}$ lot which is accessible to water and electric supply. Rental for the lot was PhP2,500 per month with the agreement that all lot developments automatically go to the landowner after the 10year project. An advanced payment of $\mathrm{PhP} 30,000$ corresponding to one (1) year rental was effected during the construction of infrastructures. All the necessary equipment, labware and initially required chemicals were purchased prior to the commencement of operation. Makapuno nuts were bought at $\mathrm{PhP} 25 / \mathrm{kg}$ or approximately $\mathrm{PhP} 16.65 / \mathrm{pc}$ assuming that three (3) nuts weigh two (2) $\mathrm{kg}$. For the 1,200 embryos needed each month, the projects spend PhP20,000/month for the Makapuno nuts. Establishment and maintenance of seedlings in vitro involved the use of coir dust ( $\mathrm{PhP} 25.00 /$ sack) black polypropylene bags for potting out, pesticides and other minor things. These were estimated at $\mathrm{PhP} 2,520 / \mathrm{mo}$. Ex vitro establishment and hardening of seedlings in the screenhouse and nursery before they were dispatched took a period of 6 months.

For the project involving cut off age of 4 month for in vitro incubation, 2 laboratory and 2 nursery workers were hired at $\mathrm{PhP} 6,000$ and 
Figure 7. a) 3 month-old Makapuno seedlings with unopened leaves; b) same age of Makapuno seedling with opened leaves; c) 4 month-old Makapuno seedlings in long test tubes ready for soil establishment; and d) 5 month-old Makapuno seedlings in milk bottles with extended plastic cover

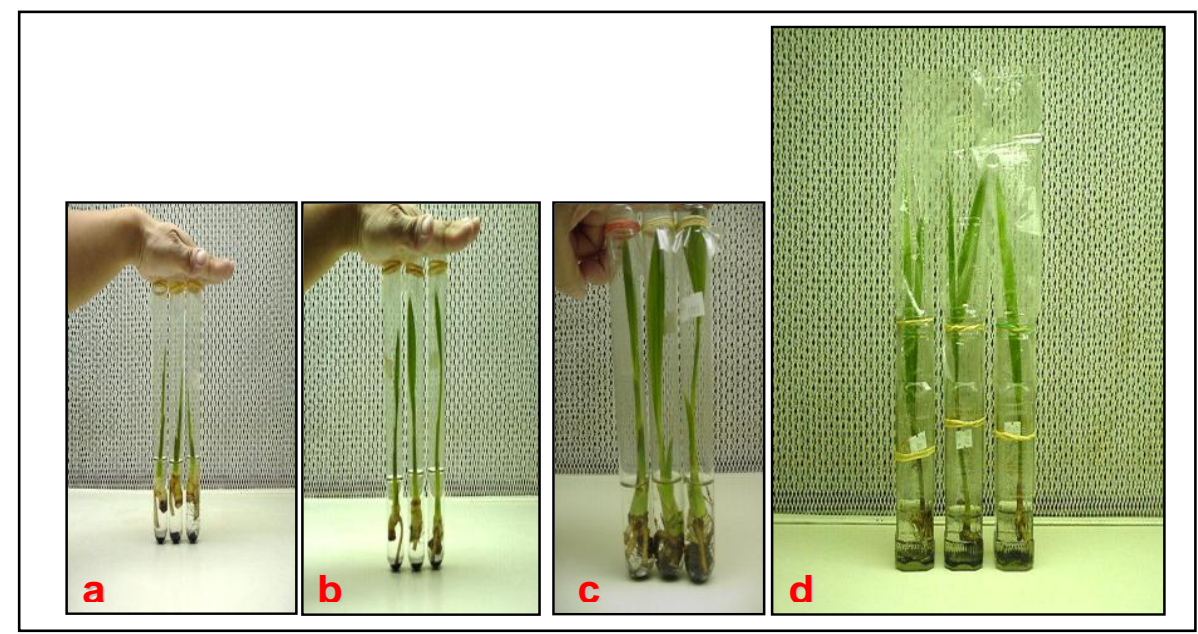

Figure 8. Comparative growth of completely hardened ECM seedlings produced using the new and current production scheme

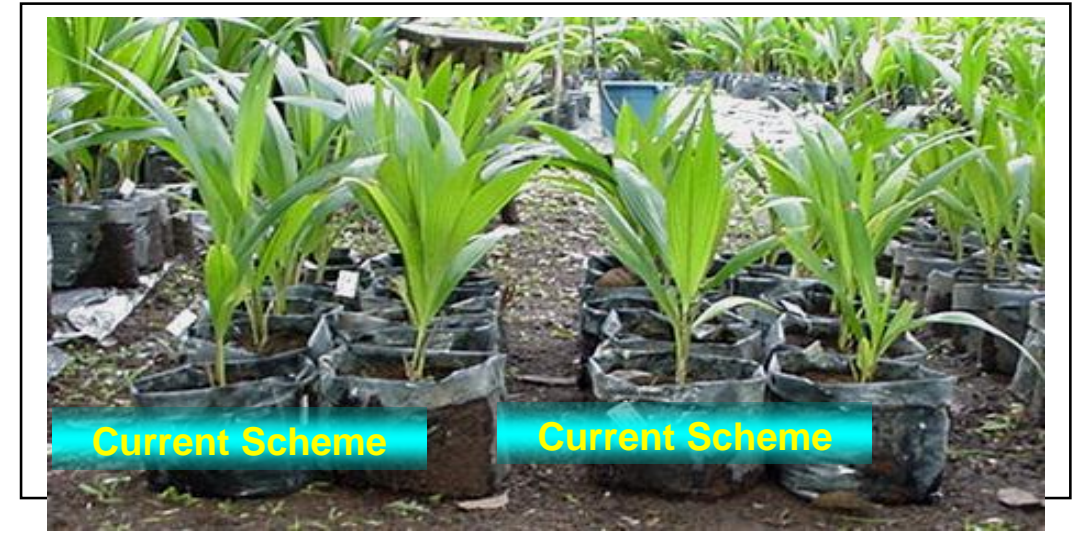

Figure 9. Humidity chamber for ex vitro establishment of in vitro Makapuno seedlings

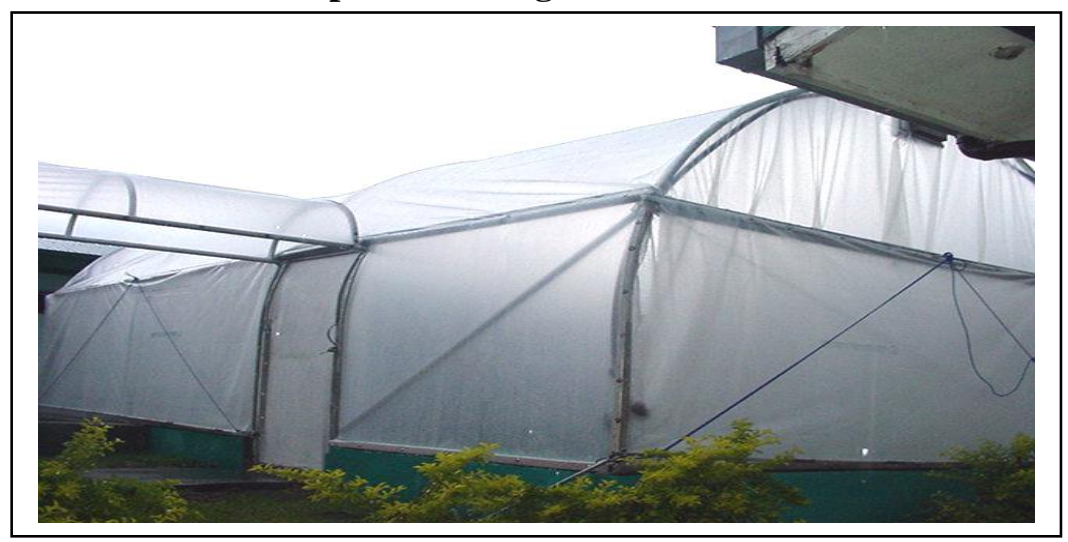


Table 12. Different developmental stages of the original and revised Makapuno Embryo Culture protocol

\begin{tabular}{|c|c|c|c|c|c|c|c|c|c|c|c|c|c|}
\hline \multirow{2}{*}{ Protocol } & \multicolumn{13}{|c|}{ Culture Stages (months) } \\
\hline & 1 & 2 & 3 & 4 & 5 & 6 & 7 & 8 & 9 & 10 & 11 & 12 & 13 \\
\hline \multirow[b]{2}{*}{ ORIGINAL } & \multicolumn{7}{|c|}{ In vitro stage } & \multicolumn{6}{|c|}{ Ex vitro stage } \\
\hline & $\begin{array}{l}\text { Germina- } \\
\text { tion }\end{array}$ & \multicolumn{6}{|c|}{ Further growth } & $\begin{array}{c}\text { Establis } \\
\text { hment }\end{array}$ & \multicolumn{5}{|c|}{ Further growth and hardening } \\
\hline \multirow[b]{2}{*}{ PROPOSED } & \multicolumn{4}{|c|}{ In vitro stage } & \multicolumn{6}{|c|}{ Ex vitro stage } & & & \\
\hline & $\begin{array}{l}\text { Germina- } \\
\text { tion }\end{array}$ & & her gr & & $\begin{array}{c}\text { Establish } \\
\text { ment }\end{array}$ & \multicolumn{5}{|c|}{ Further growth and hardening } & & & \\
\hline
\end{tabular}

Table 13. NPV, BCR, IRR and PP for a 10-year Makapuno production project involving 4 months in vitro incubation at different discount factors (DF) and selling prices of seedlings

\begin{tabular}{|c|c|c|c|c|}
\hline $\begin{array}{l}\text { SELLING } \\
\text { PRICE OF } \\
\text { ECM }(P h P)\end{array}$ & PARAMETER & $7 \% \mathrm{DF}$ & $10 \% \mathrm{DF}$ & $15 \% \mathrm{DF}$ \\
\hline \multirow{4}{*}{500} & Present Value & $16,052,586.74$ & $13,601,842.17$ & $10,487,381.03$ \\
\hline & BCR & 3.36 & 3.22 & 3.01 \\
\hline & IRR (\%) & \multicolumn{3}{|c|}{102.51} \\
\hline & Payback Period $(y r)$ & \multicolumn{3}{|c|}{3.33} \\
\hline \multirow{4}{*}{400} & Present Value & $11,556,355.69$ & $9,723,208.40$ & $7,395,606.75$ \\
\hline & BCR & 2.70 & 2.59 & 2.42 \\
\hline & $\operatorname{IRR}(\%)$ & \multicolumn{3}{|c|}{81.46} \\
\hline & Payback Period $(y r)$ & \multicolumn{3}{|c|}{3.95} \\
\hline \multirow{4}{*}{300} & Present Value & $7,060,124.64$ & $5,844,574.63$ & $4,303,832.47$ \\
\hline & BCR & 2.04 & 1.96 & 1.82 \\
\hline & $\operatorname{IRR}(\%)$ & \multicolumn{3}{|c|}{57.92} \\
\hline & Payback Period $(y r)$ & \multicolumn{3}{|c|}{4.97} \\
\hline
\end{tabular}


PhP5,000 per month with an annual year-end bonus equivalent to one (1) month's salary. An annual $10 \%$ increase in salaries of project staff was added as an incentive to keep them until the end of the project; turn over of staff would hamper smooth implementation of the project. Procurement of nuts and initiation of embryos were discontinued 6 months before the end of the project. The final 6 months of the project were purely devoted to ex vitro establishment. The cost of laboratory chemicals varied each year depending on the rate of consumption of each chemical being used. The cost of laboratory chemicals amounted to PhP252,346.00 for the whole duration of the project. Distilled water was bought at $\mathrm{PhP} 30.00 /$ liter amounting to PhP2,088.00/ month for an estimated 69.6 liters utilized monthly. Cost of tap water was PhP600.00/ month (PhP300.00 for the lab and $\mathrm{PhP} 300$ for the screenhouse and nursery. Cost of electricity, estimated at $\mathrm{PhP} 8.50 / \mathrm{KWH}$, was PhP3,151.68/ mo. Other items used in the laboratory such as LPG, plastics bags, rubber bands and detergents were estimated to cost $\mathrm{PhP} 1,470 / \mathrm{mo}$.

For the project involving a seven (7) month cut-off age for in vitro incubation, four (4) laboratory and two (2) screenhouse and nursery workers were hired at the same rate and the same monetary incentives. The longer incubation period of seedlings in vitro and the intricate procedure involved in the shift from the use of test tube to wide-mouth bottle (with plastic bag extension) necessitated hiring of an additional 2 workers in the laboratory. Besides, more labor is needed in the preparation and sterilization of nutrient media. The cost of laboratory chemicals amounted to PhP979,824.00 for the whole duration of the project. This amount was almost four (4) times the cost of chemicals for the new protocol ( $\mathrm{PhP} 252,346.00)$. The cost of distilled water amounted to $\mathrm{PhP9}, 648.00 /$ month for an estimated 321.6 liters utilized monthly. This volume of distilled water was 4.62 times higher than the monthly requirement of 69.6 liters for the project involving the modified protocol. Longer in vitro incubation and the use of bigger culture vessels required the use of more medium. Consequently, more distilled water was needed.
Cost of electricity, estimated at $\mathrm{PhP5}, 346.88 /$ month was also approximately $70 \%$ higher than the cost for the project involving the modified protocol. Cost of tap water was $\mathrm{PhP} 750.00 /$ month $(\mathrm{PhP} 450.00$ for the lab and PhP300 for the screenhouse and nursery). Increased requirement for water was expected with longer incubation period of seedlings in vitro. Other items used in the laboratory such as LPG, plastics bags, rubber bands and detergents were estimated to cost $\mathrm{PhP3}, 360 / \mathrm{mo}$. This is more than double of the cost incurred when the modified protocol is used.

Cash inflows were computed from sale of the ECM seedlings using PhP500, 400 and 300 selling prices. Sale of Makapuno meat at PhP5.00/kg of split nuts (after the collection of the embryos) was also considered.

Annual cash flows of costs and benefits for the 10-year Makapuno production project involving four (4) month and seven (7) month passages period in vitro are presented in Annex Tables 1 and 2. Understandably, the investment analysis revealed higher values for the three (3) investment decision tools (NPV, BCR and IRR) when the shortened Makapuno embryo culture cycle was considered (Tables 13 and 14). Moreover, a shorter PP was achieved with use of the shortened ECM production scheme.

At a selling price of PhP500 per ECM seedling, an IRR of $102.51 \%$ was realized when the shortened protocol was used (Table 13). This value is about $64 \%$ higher than the estimated value for the project involving the currently used protocol. Using the current protocol in 2002, ECM production with a capacity of 6000 embryos resulted to an IRR of only $26.80 \%$ and BCR of 2.11 (Areza-Ubaldo et al., 2003). Using the new production scheme, the project gave net benefits with present values of PhP16,052,586.74, PhP13,601,842.17, and $\mathrm{PhP} 10,487,381.03$ at $7 \%, 10 \%$ and $15 \%$ discount factors, respectively. Considering the BCR, every PhP1.00 that will be invested will return a benefit of 3.36, 3.22 and 3.01 at $7 \%$, $10 \%$ and $15 \%$ discount factors. All these values were lower than their corresponding values 
when the old protocol was used. The PP for the new protocol was estimated at 40 months which was approximately 16 months earlier than the PP of 56 months for the old protocol. This was much shorter than the 1999 estimate of 62 months (PSMSI, 1999).

With all these values of profitability measures, the new scheme clearly outruns the current ECM production protocol. Nevertheless, both schemes remain profitable even at a low ECM selling price of $\mathrm{PhP} 300$ per seedling.

Break-even analysis was done using both marginal (i.e., only variable costs were considered) and full (i.e., fixed and variable costs were considered) costing considering the same assumptions used in the investment analysis. Break-even analysis involving marginal costing would be useful for entrepreneurs who are already operating a tissue culture laboratory and would like to expand its operation on ECM production. On the other hand, full costing analysis would benefit those who do not have existing tissue culture laboratory facilities

With marginal costing, ECM production projects running for 10 years gave break even prices of $\mathrm{PhP1} 12.07$, PhP138.90, PhP150.32, PhP175.49, PhP203.66, PhP228.98, and $\mathrm{PhP} 255.77$ for $4,5,6,7,8,9$, and 10 month durations of in vitro incubations, respectively (Table 15). These measures will give existing plant tissue culture laboratory operators an idea of how much they will sell their ECM seedlings for if they decide to include Makapuno embryo culture in their endeavor. The break even prices increased as the duration of in vitro incubation is prolonged. An average of PhP23.94/seedling was lost for every 1 month delay in ex vitro establishment of seedlings. This is equivalent to a monthly loss of $\mathrm{PhP} 14,364$ considering the 600 seedlings produced per month.

With full costing, ECM production projects running for 10 years gave break-even prices of PhP134.96, PhP162.00, PhP173.63, PhP199.01, $\mathrm{PhP} 227.41, \mathrm{PhP} 252.95$, and PhP279.98 for 4, 5, $6,7,8,9$, and 10 month durations of in vitro incubations, respectively (Table 16). The breakeven prices increased as the duration of in vitro incubation is prolonged. An average of
$\mathrm{PhP} 24.17 /$ seedling was lost for every 1 month delay in ex vitro establishment of seedlings. This is equivalent to a monthly loss of $\mathrm{PhP} 14,502$ for the project considering the 600 seedlings produced per month. Using the current protocol, analysis of a 10 year ECM production project with a capacity of 6,000 embryos cultured per month resulted to a 2002 breakeven price of $\mathrm{PhP} 265.45$ (Areza-Ubaldo et al., 2003).

Understandably, full costing gave higher break-even prices than marginal costing because the costs of infrastructure and equipment were added in the full-cost analysis. Nevertheless, it is clear that Makapuno seedling production involving either full or marginal costing is highly profitable considering the current price of PhP500-1,000 per seedling.

\section{Conclusion and Recommendations}

With the improvement in the ambient environment for ex vitro establishment of in vitro grown seedlings it was found that seedlings with at least one (1) partially or fully exposed true leaf and one (1) primary root with or without lateral growths are very much ready for soil establishment. The use of 1:1 soilcocopeat mixture as soil support medium together with a good headspace provided by communal humidity tent has assured higher ex vitro survival rate of in vitro seedlings even at an earlier age of three (3) month after initiation of embryos.

Supported by experimental results and analyses of data from previous studies, this paper recommends modifications on the existing Makapuno embryo culture protocol by shortening the in vitro culture duration to four (4) months from the earlier duration of seven (7) months. The modifications also include simplification of the in vitro cultural practice by doing away with the plastic bag extensions attached to the culture bottles during transferring since 4 month-old in vitro seedlings can still be accommodated in long test tubes. Likewise, ex vitro establishment procedure is modified by using non-sterilized 1:1 soilcocopeat mixture as soil support medium and by 
Table 14. NPV, BCR, IRR and PP of a 10-year Makapuno production project involving 7 months in vitro incubation at different $\mathrm{DF}$ and selling prices of seedlings

\begin{tabular}{|c|c|c|c|c|}
\hline $\begin{array}{l}\text { SELLING } \\
\text { PRICE OF } \\
\text { ECM }(P h P) \\
\end{array}$ & PARAMETER & $7 \% \mathrm{DF}$ & $10 \% \mathrm{DF}$ & $15 \% \mathrm{DF}$ \\
\hline \multirow{4}{*}{500} & Present Value & $12,242,698.83$ & $10,143,693.92$ & $7,494,096.73$ \\
\hline & $\mathrm{BCR}$ & 2.25 & 2.16 & 2.00 \\
\hline & $\operatorname{IRR}(\%)$ & \multicolumn{3}{|c|}{62.67} \\
\hline & Payback Period $(y r)$ & \multicolumn{3}{|c|}{4.69} \\
\hline \multirow{4}{*}{400} & Present Value & $8,577,365.72$ & $6,988,211.65$ & $4,984,366.42$ \\
\hline & $\mathrm{BCR}$ & 1.94 & 1.85 & 1.71 \\
\hline & IRR $(\%)$ & \multicolumn{3}{|c|}{48.60} \\
\hline & Payback Period $(y r)$ & \multicolumn{3}{|c|}{5.58} \\
\hline \multirow{4}{*}{300} & Present Value & $4,245,690.53$ & $3,268,255.57$ & $2,042,308.59$ \\
\hline & BCR & 1.46 & 1.40 & 1.29 \\
\hline & IRR $(\%)$ & \multicolumn{3}{|c|}{30.63} \\
\hline & Payback Period $(y r)$ & \multicolumn{3}{|c|}{7.05} \\
\hline
\end{tabular}

Table 15. Break-even price analysis for a 10-Year Marginal Cost ECM Production using 4-10 month passage in vitro

\begin{tabular}{|c|c|c|c|c|c|c|c|}
\hline \multirow{2}{*}{ ITEM } & \multicolumn{7}{|c|}{ COST AT VARIOUS PASSAGE PERIODS IN VITRO $(P h P)$} \\
\hline & 4 month & 5 month & 6 month & 7 month & 8 month & 9 month & 10 month \\
\hline \multicolumn{8}{|l|}{ INPUT } \\
\hline Labwares & $229,628.00$ & $253,085.00$ & $276,543.00$ & $300,000.00$ & $323,457.00$ & $339,096.00$ & $370,372.00$ \\
\hline Salaries and wages & $3,979,300.00$ & $4,907,500.00$ & $4,921,500.00$ & $5,832,900.00$ & $6,768,900.00$ & $7,638,900.00$ & $8,556,900.00$ \\
\hline Lab Chemicals & $252,346.00$ & $501,058.00$ & $751,282.00$ & $979,824.00$ & $1,238,492.00$ & $1,476,438.00$ & $1,718,718.00$ \\
\hline Makapuno nuts & $2,220,000.00$ & $2,200,000.00$ & $2,180,000.00$ & $2,160,000.00$ & $2,140,000.00$ & $2,120,000.00$ & $2,100,000.00$ \\
\hline Distilled water & $231,768.00$ & $506,880.00$ & $776,952.00$ & $1,041,984.00$ & $1,301,976.00$ & $1,556,928.00$ & $1,806,840.00$ \\
\hline Electricity & $359,291.52$ & $517,614.72$ & $563,579.52$ & $609,544.32$ & $767,867.52$ & $813,832.32$ & $859,797.12$ \\
\hline Tap water & $68,400.00$ & $73,400.00$ & $78,300.00$ & $83,100.00$ & $87,800.00$ & $92,400.00$ & $96,900.00$ \\
\hline $\begin{array}{l}\text { Maintenance of seedlings in } \\
\text { the screenhouse and nursery }\end{array}$ & $292,320.00$ & $289,800.00$ & $287,280.00$ & $284,760.00$ & $282,240.00$ & $279,720.00$ & $277,200.00$ \\
\hline Other consumables & $163,170.00$ & $231,000.00$ & $297,570.00$ & $362,880.00$ & $426,930.00$ & $489,720.00$ & $551,250.00$ \\
\hline Total Input & $7,796,223.52$ & $9,480,337.72$ & $10,133,006.52$ & $11,654,992.32$ & $13,337,662.52$ & $14,807,034.32$ & $16,337,977.12$ \\
\hline \multicolumn{8}{|l|}{ OUTPUT } \\
\hline No of ECM produced & 66,000 & 65,400 & 64,800 & 64,200 & 63,600 & 63,000 & 62,400 \\
\hline Sale from Makapuno meat & $399,600.00$ & $396,000.00$ & $392,400.00$ & $388,800.00$ & $385,200.00$ & $381,600.00$ & $378,000.00$ \\
\hline $\begin{array}{l}\text { BREAK-EVEN PRICE PER } \\
\text { SEEDLING }(P h P)\end{array}$ & 112.07 & 138.90 & 150.32 & 175.49 & 203.66 & 228.98 & 255.77 \\
\hline
\end{tabular}


Table 16. Break-even price analysis for a 10-Year Full Cost ECM Production using 4-10 month passage in vitro

\begin{tabular}{|c|c|c|c|c|c|c|c|}
\hline \multirow{2}{*}{ ITEM } & \multicolumn{7}{|c|}{ COST AT VARIOUS PASSAGE PERIODS IN VITRO $(P h P)$} \\
\hline & 4 month & 5 month & 6 month & 7 month & 8 month & 9 month & 10 month \\
\hline \multicolumn{8}{|l|}{ INPUT } \\
\hline $\begin{array}{l}\text { Laboratory, screenhouse } \\
\text { and nursery }\end{array}$ & $720,000.00$ & $720,000.00$ & $720,000.00$ & $720,000.00$ & $720,000.00$ & $720,000.00$ & $720,000.00$ \\
\hline Laboratory equipment & $490,500.00$ & $490,500.00$ & $490,500.00$ & $490,500.00$ & $490,500.00$ & $490,500.00$ & $490,500.00$ \\
\hline Land Rental (500 sqm) & $300,000.00$ & $300,000.00$ & $300,000.00$ & $300,000.00$ & $300,000.00$ & $300,000.00$ & $300,000.00$ \\
\hline Labwares & $229,628.00$ & $253,085.00$ & $276,543.00$ & $300,000.00$ & $323,457.00$ & $339,096.00$ & $370,372.00$ \\
\hline Salaries and wages & $3,979,300.00$ & $4,907,500.00$ & $4,921,500.00$ & $5,832,900.00$ & $6,768,900.00$ & $7,638,900.00$ & $8,556,900.00$ \\
\hline Lab Chemicals & $252,346.00$ & $501,058.00$ & $751,282.00$ & $979,824.00$ & $1,238,492.00$ & $1,476,438.00$ & $1,718,718.00$ \\
\hline Makapuno nuts & $2,220,000.00$ & $2,200,000.00$ & $2,180,000.00$ & $2,160,000.00$ & $2,140,000.00$ & $2,120,000.00$ & $2,100,000.00$ \\
\hline Distilled water & $231,768.00$ & $506,880.00$ & $776,952.00$ & $1,041,984.00$ & $1,301,976.00$ & $1,556,928.00$ & $1,806,840.00$ \\
\hline Electricity & $359,291.52$ & $517,614.72$ & $563,579.52$ & $609,544.32$ & $767,867.52$ & $813,832.32$ & $859,797.12$ \\
\hline Tap water & $68,400.00$ & $73,400.00$ & $78,300.00$ & $83,100.00$ & $87,800.00$ & $92,400.00$ & $96,900.00$ \\
\hline $\begin{array}{l}\text { Maintenance of } \\
\text { seedlings ex vitro }\end{array}$ & $292,320.00$ & $289,800.00$ & $287,280.00$ & $284,760.00$ & $282,240.00$ & $279,720.00$ & $277,200.00$ \\
\hline Other consumables & $163,170.00$ & $231,000.00$ & $297,570.00$ & $362,880.00$ & $426,930.00$ & $489,720.00$ & $551,250.00$ \\
\hline Total Input & $9,306,723.52$ & $10,990,837.72$ & $11,643,506.52$ & $13,165,492.32$ & $14,848,162.52$ & $16,317,534.32$ & $17,848,477.12$ \\
\hline \multicolumn{8}{|l|}{ OUTPUT } \\
\hline No of ECM produced & 66,000 & 65,400 & 64,800 & 64,200 & 63,600 & 63,000 & 62,400 \\
\hline $\begin{array}{l}\text { Sale from Makapuno } \\
\text { meat }\end{array}$ & $399,600.00$ & $396,000.00$ & $392,400.00$ & $388,800.00$ & $385,200.00$ & $381,600.00$ & $378,000.00$ \\
\hline $\begin{array}{l}\text { BREAK-EVEN } \\
\text { PRICE PER } \\
\text { SEEDLING }(P h P) \\
\end{array}$ & 134.96 & 162.00 & 173.63 & 199.01 & 227.41 & 252.95 & 279.98 \\
\hline
\end{tabular}

using a communal humidity chamber instead of the individual plastic bag covers to maintain high relative humidity for the establishing seedlings. With the shortening and simplification of the in vitro cultural practice as well as modification of the ex vitro establishment procedure, ECM production has been made faster and cheaper.

Investment analysis of a 10-year production project revealed a high IRR of $102.51 \%$ for the new production scheme when the produced seedlings are sold at PCArecommended price of PhP500.00 per seedling. This is about $64 \%$ higher than the value for the old production scheme. Using the new production scheme, the project has a BCR of 2.16 corresponding to a net present value of $\mathrm{PhP} 10.14 \mathrm{M}$ using $10 \%$ discount factor.
Using marginal and full costing, comparative break-even prices of ECM seedling for various production schemes involving 4-10 month culture durations in vitro showed the profitability of the ECM seedling production business, considering the PhP500-1,000 current price of ECM seedlings. The computed breakeven prices will also be a good decision tool for ECM seedling producers. High selling cost would mean more profit. On the other hand, lower but profitable cost would attract more buyers resulting to increase in demand and therefore, massive planting of ECM in the country. This will eventually pave the way for the development of the Makapuno Industry in the Philippines. 


\section{Acknowledgement}

The authors would like to thank the ACIAR for funding the initial activities of this research through the ACIAR-funded project entitled, Coconut Tissue Culture for Clonal Propagation and Safe Germplasm Exchange. Gratitude is also extended to DOST-PCARRD for providing the necessary funds for the construction of a humidity chamber and repair of a screenhouse which were used in the confirmatory soil establishment part of the experiments. Credit is also due to Mrs. Mercy Osiana for providing some necessary ECM production data and to Misters Ernesto Persia and Renato Obaña for their help in the ex vitro establishment experiments. Special thanks is extended to Dr. Hugh Harries for editing this paper.

\section{References}

Areza-Ubado MBB, Rillo EP and Cueto CA. 2003. Application of the improved embryo cultural protocol for commercial production of Makapuno seedlings. Philippine Journal of Science, 132(1):111.

PSMSI. 1999. Feasibility Study on Embryocultured Makapuno Production. Postharvest Systems and Management Services, Inc.

Verdeil J-L. 1996. Study of vitroplant physiology using zygotic embryos in vitro as a model. In: Second Annual Report of the EC-STD3 Project "Coconut: development of methods for the clonal propagation of elite, disease resistant palms by somatic embryogenesis". pp 7476. 
Annex Table 1. Investment analysis of a full cost 10-Year ECM Production using the proposed 4 month passage in vitro

\begin{tabular}{|c|c|c|c|c|c|c|c|c|c|c|c|c|}
\hline & Yr0 & Yr 1 & Yr 2 & Yr3 & 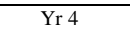 & Yr 5 & 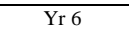 & Yr 7 & Yr 8 & Yr 9 & 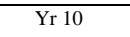 & TOTAL \\
\hline \multicolumn{13}{|l|}{$\overline{\text { INPUT }}$} \\
\hline $\begin{array}{l}\text { Laboratory, screenhouse and } \\
\text { nursery }\end{array}$ & $720,000.00$ & & & & & & & & & & & $720,000.00$ \\
\hline Laboratory equipment & $490,500.00$ & & & & & & & & & & & $490,500.00$ \\
\hline Cost of Land rental (500 sqm) & $30,000.00$ & $30,000.00$ & $30,000.00$ & $30,000.00$ & $30,000.00$ & $30,000.00$ & $30,000.00$ & $30,000.00$ & $30,000.00$ & $30,000.00$ & 0.00 & $300,000.00$ \\
\hline Labwares & $229,628.00$ & & & & & & & & & & & $229,628.00$ \\
\hline Salaries and wages & & $276,000.00$ & $314,600.00$ & $343,200.00$ & $371,800.00$ & $400,400.00$ & $429,000.00$ & $457,600.00$ & $486,200.00$ & $514,800.00$ & $385,700.00$ & $3,979,300.00$ \\
\hline Lab Chemicals & $63,170.00$ & $27,158.00$ & $22,248.00$ & $23,192.00$ & $22,152.00$ & $29,318.00$ & $16,122.00$ & $29,318.00$ & $19,668.00$ & 0.00 & 0.00 & $252,346.00$ \\
\hline Makapuno nuts & & $240,000.00$ & $240,000.00$ & $240,000.00$ & $240,000.00$ & $240,000.00$ & $240,000.00$ & $240,000.00$ & $240,000.00$ & $240,000.00$ & $60,000.00$ & $2,220,000.00$ \\
\hline Distilled water & & $21,627.00$ & $25,056.00$ & $25,056.00$ & $25,056.00$ & $25,056.00$ & $25,056.00$ & $25,056.00$ & $25,056.00$ & $25,056.00$ & $9,693.00$ & $231,768.00$ \\
\hline Electricity & & $37,820.16$ & $37,820.16$ & $37,820.16$ & $37,820.16$ & $37,820.16$ & $37,820.16$ & $37,820.16$ & $37,820.16$ & $37,820.16$ & $18,910.08$ & $359,291.52$ \\
\hline Tap water & & $5,700.00$ & $7,200.00$ & $7,200.00$ & $7,200.00$ & $7,200.00$ & $7,200.00$ & $7,200.00$ & $7,200.00$ & $7,200.00$ & $5,100.00$ & $68,400.00$ \\
\hline Maintenance of seedlings $e x$ vitro & & $20,160.00$ & $30,240.00$ & $30,240.00$ & $30,240.00$ & $30,240.00$ & $30,240.00$ & $30,240.00$ & $30,240.00$ & $30,240.00$ & $30,240.00$ & $292,320.00$ \\
\hline Other consumables & & $17,640.00$ & $17,640.00$ & $17,640.00$ & $17,640.00$ & $17,640.00$ & $17,640.00$ & $17,640.00$ & $17,640.00$ & $\begin{array}{ll}17,640.00 \\
\end{array}$ & $4,410.00$ & $163,170.00$ \\
\hline Total Input & $1,374,298.00$ & $676,105.16$ & $724,804.16$ & $754,348.16$ & $781,908.16$ & $817,674.16$ & $833,078.16$ & $874,874.16$ & $893,824.16$ & $902,756.16$ & $514,053.08$ & $9,306,723.52$ \\
\hline OUTPUT & & & & & & & & & & & & \\
\hline Sale from ECM (PhP 500) & & $600,000.00$ & $3,600,000.00$ & $3,600,000.00$ & $3,600,000.00$ & $3,600,000.00$ & $3,600,000.00$ & $3,600,000.00$ & $3,600,000.00$ & $3,600,000.00$ & $3,600,000.00$ & $33,000,000.00$ \\
\hline Sale from ECM (PhP 400) & & $480,000.00$ & $2,880,000.00$ & $2,880,000.00$ & $2,880,000.00$ & $2,880,000.00$ & $2,880,000.00$ & $2,880,000.00$ & $2,880,000.00$ & $2,880,000.00$ & $2,880,000.00$ & $26,400,000.00$ \\
\hline Sale from ECM (PhP 300) & & $360,000.00$ & $2,160,000.00$ & $2,160,000.00$ & $2,160,000.00$ & $2,160,000.00$ & $2,160,000.00$ & $2,160,000.00$ & $2,160,000.00$ & $2,160,000.00$ & $2,160,000.00$ & $19,800,000.00$ \\
\hline Sale from Makapuno meat & & $43,200.00$ & $43,200.00$ & $43,200.00$ & $43,200.00$ & $43,200.00$ & $43,200.00$ & $43,200.00$ & $43,200.00$ & $43,200.00$ & $10,800.00$ & $399,600.00$ \\
\hline $\begin{array}{l}\text { Residual value (equip \& labwares, } \\
25 \%)\end{array}$ & & & & & & & & & & & $180,032.00$ & $180,032.00$ \\
\hline Total Output (PhP 500) & & $643,200.00$ & $3,643,200.00$ & $3,643,200.00$ & $3,643,200.00$ & $3,643,200.00$ & $3,643,200.00$ & $3,643,200.00$ & $3,643,200.00$ & $3,643,200.00$ & $3,790,832.00$ & $33,579,632.00$ \\
\hline Total Output (PhP 400) & & $523,200.00$ & $2,923,200.00$ & $2,923,200.00$ & $2,923,200.00$ & $2,923,200.00$ & $2,923,200.00$ & $2,923,200.00$ & $2,923,200.00$ & $2,923,200.00$ & $3,070,832.00$ & $26,979,632.00$ \\
\hline Total Output (PhP 300) & & $403,200.00$ & $2,203,200.00$ & $2,203,200.00$ & $2,203,200.00$ & $2,203,200.00$ & $2,203,200.00$ & $2,203,200.00$ & $2,203,200.00$ & $2,203,200.00$ & $2,350,832.00$ & $20,379,632.00$ \\
\hline
\end{tabular}


Annex Table 2. Investment analysis of a full cost 10-Year ECM Production using in vitro incubation period

\begin{tabular}{|c|c|c|c|c|c|c|c|c|c|c|c|c|}
\hline & $\mathrm{Yr} 0$ & Yr 1 & $\mathrm{Yr} 2$ & $\mathrm{Yr} 3$ & $\mathrm{Yr} 4$ & Yr 5 & Yr 6 & Yr 7 & $\operatorname{Yr} 8$ & $\operatorname{Yr} 9$ & Yr 10 & TOTAL \\
\hline \multicolumn{13}{|l|}{ INPUT } \\
\hline $\begin{array}{l}\text { Laboratory, screenhouse and } \\
\text { nursery }\end{array}$ & $720,000.00$ & & & & & & & & & & & $720,000.00$ \\
\hline Laboratory equipment & $490,500.00$ & & & & & & & & & & & $490,500.00$ \\
\hline Cost of Land rental (500 sqm) & $30,000.00$ & $30,000.00$ & $30,000.00$ & $30,000.00$ & $30,000.00$ & $30,000.00$ & $30,000.00$ & $30,000.00$ & $30,000.00$ & $30,000.00$ & 0.00 & $300,000.00$ \\
\hline Labwares & $300,000.00$ & & & & & & & & & & & $300,000.00$ \\
\hline Salaries and wages & & $358,000.00$ & $486,200.00$ & $530,400.00$ & $574,600.00$ & $618,800.00$ & $663,000.00$ & $707,200.00$ & $751,400.00$ & $795,600.00$ & $347,700.00$ & $5,832,900.00$ \\
\hline Lab Chemicals & $153,798.00$ & $110,556.00$ & $94,008.00$ & $112,602.00$ & $110,556.00$ & $90,348.00$ & $110,556.00$ & $102,924.00$ & $94,476.00$ & 0.00 & & $979,824.00$ \\
\hline Makapuno nuts & & $240,000.00$ & $240,000.00$ & $240,000.00$ & $240,000.00$ & $240,000.00$ & $240,000.00$ & $240,000.00$ & $240,000.00$ & $240,000.00$ & 0.00 & $2,160,000.00$ \\
\hline Distilled water & & $74,547.00$ & $115,776.00$ & $115,776.00$ & $115,776.00$ & $115,776.00$ & $115,776.00$ & $115,776.00$ & $115,776.00$ & $115,776.00$ & $41,229.00$ & $1,041,984.00$ \\
\hline Electricity & & $64,162.56$ & $64,162.56$ & $64,162.56$ & $64,162.56$ & $64,162.56$ & $64,162.56$ & $64,162.56$ & $64,162.56$ & $64,162.56$ & $32,081.28$ & $609,544.32$ \\
\hline Tap water & & $5,850.00$ & $9,000.00$ & $9,000.00$ & $9,000.00$ & $9,000.00$ & $9,000.00$ & $9,000.00$ & $9,000.00$ & $9,000.00$ & $5,250.00$ & $83,100.00$ \\
\hline Maintenance of seedlings ex vitro & & $12,600.00$ & $30,240.00$ & $30,240.00$ & $30,240.00$ & $30,240.00$ & $30,240.00$ & $30,240.00$ & $30,240.00$ & $30,240.00$ & $30,240.00$ & $284,760.00$ \\
\hline Other consumables & & $40,320.00$ & $40,320.00$ & $40,320.00$ & $40,320.00$ & $40,320.00$ & $40,320.00$ & $40,320.00$ & $40,320.00$ & $40,320.00$ & 0.00 & $362,880.00$ \\
\hline Total Input & $1,730,798.00$ & $936,035.56$ & $1,109,706.56$ & $1,172,500.56$ & $1,214,654.56$ & $1,238,646.56$ & $1,303,054.56$ & $1,339,622.56$ & $1,375,374.56$ & $1,325,098.56$ & $456,500.28$ & $13,165,492.32$ \\
\hline OUTPUT & & & 6,600 & 7,200 & 7,200 & 7,200 & 7,200 & 7,200 & 7,200 & 7,200 & 7,200 & 64,200 \\
\hline Sale from ECM (PhP 500) & & 0.00 & $3,300,000.00$ & $3,600,000.00$ & $3,600,000.00$ & $3,600,000.00$ & $3,600,000.00$ & $3,600,000.00$ & $3,600,000.00$ & $3,600,000.00$ & $3,600,000.00$ & $32,100,000.00$ \\
\hline Sale from ECM (PhP 400) & & 0.00 & $2,640,000.00$ & $2,880,000.00$ & $2,880,000.00$ & $2,880,000.00$ & $2,880,000.00$ & $2,880,000.00$ & $2,880,000.00$ & $2,880,000.00$ & $2,880,000.00$ & $25,680,000.00$ \\
\hline Sale from ECM (PhP 300) & & 0.00 & $1,980,000.00$ & $2,160,000.00$ & $2,160,000.00$ & $2,160,000.00$ & $2,160,000.00$ & $2,160,000.00$ & $2,160,000.00$ & $2,160,000.00$ & $2,160,000.00$ & $19,260,000.00$ \\
\hline Sale from Makapuno meat & & $43,200.00$ & $43,200.00$ & $43,200.00$ & $43,200.00$ & $43,200.00$ & $43,200.00$ & $43,200.00$ & $43,200.00$ & $43,200.00$ & 0.00 & $388,800.00$ \\
\hline $\begin{array}{l}\text { Residual value (equip \& labwares, } \\
(25 \%)\end{array}$ & & & & & & & & & & & $197,625.00$ & $197,625.00$ \\
\hline Total Output (PhP 500) & & $43,200.00$ & $3,343,200.00$ & $3,643,200.00$ & $3,643,200.00$ & $3,643,200.00$ & $3,643,200.00$ & $3,643,200.00$ & $3,643,200.00$ & $3,643,200.00$ & $3,797,625.00$ & $32,686,425.00$ \\
\hline Total Output (PhP 400) & & $43,200.00$ & $2,683,200.00$ & $2,923,200.00$ & $2,923,200.00$ & $2,923,200.00$ & $2,923,200.00$ & $2,923,200.00$ & $2,923,200.00$ & $2,923,200.00$ & $3,077,625.00$ & $26,266,425.00$ \\
\hline Total Output (PhP 300) & & $43,200.00$ & $2,023,200.00$ & $2,203,200.00$ & $2,203,200.00$ & $2,203,200.00$ & $2,203,200.00$ & $2,203,200.00$ & $2,203,200.00$ & $2,203,200.00$ & $2,357,625.00$ & $19,846,425.00$ \\
\hline
\end{tabular}

